\title{
MERCADO DE HABITAÇÃo E ESTRUTURA URBANA NA ÁREA SUBURBANA DE LISBOA
}

A última tese de doutoramento em Geografia (humana) foi a de TERESA MARGARIDA BARATA SALGUEIRO, defendida em Novembro de 1983 na Universidade de Lisboa, com aquele título. O volume policopiado, de 371 p. (339 p. de texto, 13 de bibliografia, 7 correspondendo a três anexos, 6 de indices de quadros e figuras, e 2 de indice geral da obra), profusamente ilustrado, constitui a introdução, entre nós, de um tema novo e técnicas inovadoras de investigação em Geografia urbana. $O$ tema surge na sequência da preparação especializada que a autora começou ainda era aluna da licenciatura de Geografia na Faculdade de Letras de Lisboa, e viria a prosseguir com êxito na Universidade de Chicago, sob a orientação de J. BRIAN BERRY. Nessa universidade obteve o grau de Master of Arts em finais de 1973, cerca de três anos após a licenciatura em Lisboa, obtida com uma tese sobre Torres Vedras. A vila $e$ a região (2 vols., 230 p. dactilografadas e muita ilustração apropriada). As altas classificações então alcançadas permitiram-lhe gozar da regalia legal da dispensa das provas complementares para o doutoramento.

Aceitei orientar os trabalhos de TERESA M. BARATA SAlguEIRo, que me obrigaram a prestar maior atenção à informação bibliográfica sobre o tema e a rever ideias formuladas nos anos em que me dediquei a estudos de Geografia urbana para melhor preparar a monografia sobre Luanda. Estudo de Geografia urbana, Lisboa, 1968. Nessa altura apenas foi possivel aflorar uns tantos problemas muito gerais e enunciar algumas linhas de pesquisa, sem a profundidade da metodologia seguida por TERESA M. BARATA SAlgueiro. Foi-me grato e construtivo o diálogo que estabelecemos, em numerosas sessões de trabalho, até terem sido encontradas as formas mais adequadas da apresentação e discussão dos aliciantes problemas postos pelo mercado de habitação e estrutura urbana na área suburbana de Lisboa, de Loures e Odivelas. Tais exercícios científicos e pedagógicos fizeram-me recordar outros praticados em relação a outras teses de doutoramento para as quais me pediram a intervenção, particularmente a de JORgE BARboSA GASPAR, A Area de Influência de Évora. Sistema de Funções e Lugares Centrais, Lisboa, 1972, também em geografia urbana, dando realização ao que aprendera em estágio decorrido na Universidade de Lund (Suécia).

Em p. 4, do "Prefácio», Teresa M. Barata S Algueiro informa que "este trabalho não é uma obra exaustiva; é um levantar do véu de um tema complexo que não foi possível desbravar em toda a sua extensão». E em p. 6, «embora reconheça que este trabalho deva ser continuado, visto constituir o que se apresenta apenas como um primeiro passo, julgo ter prestado um honesto contributo. Quer a nível teórico, quer metodológico, o caminho fica abertom. Oxalá assim suceda e que ela própria e outros venham a retomar as linhas de investigação propostas para melhor dilucidação da «articulação dos agentes económicos e sociais do espaço, do modo de produção do espaço (construído). Este é um campo a que os geógrafos não têm 
prestado muita atenção porque, em geral, se preocupam mais com o estudo dos efeitos desses agentes no espaço» (p. 10).

A tese é apresentada com uma Introdução, a que se seguem a formulação do objecto de estudo, a metodologia e fontes utilizadas, a caracterização da área estudada, a sua organização espacial, a variação das rendas de casa nos espaços considerados e a produção de habitação, os utentes e a estrutura da propriedade, e uma nota final de síntese das grandes ideias anteriormente expostas. A ilustração é, geralmente, de boa qualidade, e a bibliografia, adequadamente arrumada, aumenta o valor do trabalho. «Porque nos situamos na Geografia Urbana e o conhecimento do mecanismo dos preços não era um objectivo em si, mas só significativo como processo activo na estruturação da cidade, começamos por definir teoricamente esta tese" (p. 11). Ao reler esta frase ocorre-me ao espírito uma afirmação do físico atómico ROBERT OPPENHEIMER - «Nada é tão prático como a teoria» -, de certo modo paradoxal, mas que faz sentido quando se realiza que a teoria é, actualmente, uma via para a compreensão do Mundo pelo arranjo particular de interpretações de factos e experiências pessoais. A ciência constrói-se com factos, do mesmo modo que uma casa se ergue com tijolos; mas uma sobreposição de factos pode não resultar em ciência. A teoria será tomada, assim, como a forma pela qual os tijolos podem ser arrumados para a obtenção de uma estrutura coerente. E, ao mesmo tempo que explica factos, tem de ser aplicada. A autora da tese em recensão logrou construir, e bem fundamentado, o seu edifício científico. Não se limita a descrever o mundo exterior, como ele é, mas antes propõe vias pelas quais as coisas (meios e relações de produção sobre as quais repousam as estruturas sociais) podem ser modificadas.

$\mathrm{Na}$ alínea 1 da Introdução, «Estudos semelhantes» (p. 13-30), é dada uma boa resenha da vasta bibliografia relacionada com o tema da dissertação, e são evidenciadas as ideias mais importantes expendidas pelos autores citados. A leitura atenta dessa alínea facilita a penetração do texto denso da obra. Em «Formulação do objecto de estudo", ainda com carácter introdutório, as matérias estão dispostas em quatro subtítulos: Cidades e modos de produção; a renda e o padrão locativo das actividades; a habitação - factores que influenciam a escolha do sítio e segregação espacial; e algumas características do mercado de habitação (p. 31-69). Em trabalhos futuros interessará desenvolver a ideia de que "os estudos existentes sobre a habitação apontam mais para a presença de uma situação de desequilíbrio permanente do que para sucessões de períodos de equilíbrio e desequilíbrio, características da economia de mercado" (p. 61), uma vez que a teoria económica enquadra o estudo da habitação no quadro geral dos mecanismos de mercados e preços, a partir da noção de renda elaborada pela escola neoclássica.

A terceira parte, Metodologia e fontes, abrange alíneas sobre as hipóteses de trabalho, as características dos edifícios e dos fogos e a definição das unidades de análise, as características dos habitantes, equipamentos e acessibilidade (p. 70-98). Em p. 71 a autora enuncia as suas opções do seguinte modo: aplicação de rigor estatístico à recolha da informação e utilização de técnicas quantitativas no seu tratamento; articulação de conceitos teóricos à observação criteriosa e à reflexão sobre os 
factos; tratamento de um tema e não de uma região geográfica. Em resumo, pode dizer-se que foi dada preferência aos métodos quantitativos e reflexão teórica, para explicação da realiḍade social. São exemplạres as referências às dificuldades encontradas para a recolha de dados estatísticos de pormenor, imprescindíveis para a elaboração da tese, num país onde ainda faltam, infelizmente, estatísticas fundamentais; para a localização geográfica de cerca de 2500 prédios e a sua história; para a realização de perto de 720 inquéritos directos. Uma das grandes virtudes desta dissertação é, justamente, a sua preocupação didáctica. Nada se esconde, nada se distorce, para que fiquem bem claras as dificuldades, os defeitos, mas também as virtudes. Além da metodologia cautelosamente seguida, há a preocupação do estabelecimento de definição em domínios que não existem entre nós, ou estão ainda mal conhecidos. Serve como exemplo o ensaio da criação de uma tipologia da habitação (p. 87 e outras), por ora simplesmente descritiva, mas que certamente virá a ser melhorada em estudos posteriores sobre a matéria.

Iniciando a quarta parte, Caracterização da área estudada - uso do solo, formação da área metropolitana de Lisboa, a população residente, sectores de actividade da população (p. 99-157) -, coloca-se o tema no contexto demográfico do País e da Área Metropolitana de Lisboa. Uma falha na legenda da fig. 4.2 (p. 106), enreda um pouco a leitura das p. 107 a 109 acerca da distribuição dos principais tipos de edifícios nas freguesias dos concelhos de Loures e Odivelas. Mas isso é de somenos importância porque, juntamente com outros pontos menos claros, poderá ser corrigido em edição definitiva que o volume policopiado bem merece. As p. 113-114 contêm uma boa imagem da expansão urbana, embora na segunda tivesse ficado pouco evidente a relação das prováveis "consequências das duas guerras" com o movimento de passageiros na linha de Sintra. Acerca dos transportes - rodoviários e ferroviários - teria valido a pena um exercício de pesquisa sobre os resultados da divulgação do chamado "passe social» e das suas relações com a escolha do local de habitação. Em "A população residente - suas características" se demonstra mais uma vez a intensificação recente dos processos da suburbanização, em estudo suficientemente pormenorizado das relações entre o crescimento demográfico e as condições de habitação.

Em Organização espacial, a quinta parte, estão consideradas as funções centrais, a hierarquia dos lugares centrais, as dependências na aquisição de bens e serviços, o sistema de transportes colectivos (p. 158-208). Para 52 lugares foram levantados os equipamentos comerciais e de serviços, com exclusão das actividades secundárias, salvo em certos casos especiais, e assim identificadas 163 funções centrais (quadro de p. 164-166). Destas ficaram retidas 119, acerca das quais foram estudadas exaustivamente as ocorrenciais, para melhor explicação da organização do sector terciário e verificação de que nem sempre são aplicáveis, indistintamente os padrões definidos noutros contextos económicos e sociais. Assim, ressalva a autora uma certa falta de nitidez, ou mesmo contradição, das relações entre preços e estabelecimentos celulares de modernos "Centros Comerciais» (p. 161), entre localização de supermercados e distribuição de aglomerados populacionais (p. 168), entre «urbanização» e instalação 
de equipamentos (p. 172). O conjunto de observações, muito pertinentes, merece ser revisto e melhor fixado, mesmo em comparação com métodos aplicados por outros investigadores em áreas de características económicas e sociais muito diferentes. Por sucessivas aproximações talvez se possa chegar à melhor definição dos processos e fenómenos do contexto lisboeta. A alínea sobre a "Hierarquia dos lugares centrais» (p. 176-184) poderia ter ficado mais extensa, para abrigar a discussão de um aspecto que me parece muito interessante: o nível $\mathrm{V}$ dos lugares centrais, evidenciado na área estudada e que de todo escapa aos modelos christalleriano, loschiano e de outros venerados autores, talvez porque não tiveram a oportunidade de conhecerem a realidade insofismável dos loteamentos e dos bairros clandestinos quando discutiram o factor de progressão $\mathrm{K}$ do número de lugares. Ora bem, vale a pena reflectir sobre as condições políticas, económicas e sociais dos lugares e momentos em que W. CHRISTALLER, A. LOSCH e outros emitiram as suas teorias, tão do agrado dos geógrafos que se debruçam sobre os problemas da ordenação dos espaços construídos, comparando-os cuidadosamente com lugares e momentos de hoje. Fê-lo TERESA M. BARATA SAlgueIro, que sintetizou as suas ideias do seguinte modo: «Relativamente à localização dos lugares dos vários níveis identificados (fig. 5.6) verifica-se não só que constitui uma excepção à Teoria dos Lugares Centrais segundo a formulação de W. CHRISTALLER, mas também que existem contrastes entre os dois concelhos" (de Loures e Odivelas), em p. 181. Constatados os factos, é de esperar que o desafio venha a ser retomado, até a uma melhor definição de acordo com os condicionamentos locais e nacionais.

A abordagem mais directa do tema proposto, título da dissertação, é feita em $A$ variação espacial das rendas de casa (o comportamento das rendas, grupos de variáveis e rendas, os modelos gerais, análise factorial, análise factorial e regressão linear, p. 209-257), com prolongamento nas outras duas partes. As p. 214-257 correspondem à exposição do modelo de regressão linear passo a passo para a explicação da distribuição espacial dos preços das rendas por divisão assoalhada. No Anexo 20 leitor poderá ver os grupos de variáveis utilizadas no cálculo informático, distribuídas por quatro grandes conjuntos: factores sócio-económicos, equipamentos terciários e acessibilidade, tipologia dos edifícios e conforto dos fogos. No conjunto, são 74 variáveis designadas por código e com a referência às fontes de informação. Estabelecidas as matrizes de correlação, foram elaborados os modelos gerais (p. 229-235), nos lugares (p. 235-237), nas áreas urbanas e rurais (p. 237-241). Experimentados 4 modelos para o primeiro caso, 1 para o segundo e 2 para o terceiro, e analisadas as suas diferenças, a autora conclui «que o mercado de habitação de aluguer nas zonas urbanas é muito anómalo, em termos económicos de mercado. De facto, a renda não parece decorrer do ajuste da procura e da oferta (definidos em termos de características da família e do fogo). As principais causas das rendas urbanas, o tempo e a dimensão dos prédios, não são variáveis estritamente geográficas. Traduzem as características exógenas do mercado, o condicionamento das rendas e a concorrência associada à especulação, que fazem reverter para o pagamento do terreno uma parte muito elevada do preço do produto. E também de realçar que a acessibilidade só parece 
desempenhar algum papel nas zonas urbanas (atendendo à leitura possível sobre a inclusão do caminho-de-ferro nas rurais). Ao contrário dos modelos americanos, não é a distância ao centro principal que tem mais reflexo nos preços, mas sim as condiçốes de acessibilidade em transportes públicos, não só ao centro de Lisboa mas também a todos os outros locais" (p. 243). Está-se deste modo em presença de uma asserção da realidade nacional, ou pelo menos regional, que importa explorar para retirar o melhor significado das perturbações do modelo geral. $O$ emprego da análise factorial talvez tivesse sido redundante, uma vez que conduziu aos mesmos resultados obtidos com a do modelo linear de regressão passo a passo, sobretudo quando aquela análise não pôde ser levada às suas extremas consequências (p. 243-257). A revisão desta alínea conduzirá, certamente, à tentativa da fixação de terminologia adequada em língua portuguesa.

A penúltima parte, intitulada $A$ produção de habitação - os proprietários fundiários, os promotores de urbanização, e os construtores (p. 258-301), - encarada como um processo de transformação do espaço, salienta os papéis dos vários intervenientes. Teria interesse a amostragem cartográfica das relações entre terra cultivada e terra expectante (p. 261), sobretudo no momento actual, de transformações rápidas da paisagem. De igual modo seria oportuna a cartografia da variação da dimensão da propriedade nos dois concelhos estudados porque, na opinião da autora, «não parece poder ser explicada senão por razôes do passado: uso agrícola e heranças» (p. 263). Mas, na verdade, não haverá outras razões? Na alínea acerca dos «Promotores de urbanização" ficou o campo aberto para o estabelecimento dos pontos fundamentais para a elaboração de um modelo de distribuição dos empréstimos para habitação. Tendo em conta as grandes modificações ocorridas nos últimos vinte anos, mas sobretudo após 1974, com a nacionalização da banca e de certas indústrias fundamentais para a construção civil, particularmente relacionadas com o mercado de habitação, continua por fazer a história das sociedades imobiliárias e dos grupos financeiros. Os problemas são difíceis de abordar do ponto de vista da pesquisa científica e a autora não o esconde. Pelo contrário, denuncia-os quando os enuncia. A par disso, assinala outros não menos importantes, como quando afirma: "o loteador clandestino apresenta a resposta eficaz, não diremos correcta, à procura insolvente. Expande-se, porque a estrutura do sector o justifica, e até necessita dele. Funciona como um submercado tão necessário como qualquer outro» (p. 271).

Os utentes e a estrutura da propriedade urbana (dimensão da propriedade, propriedade horizontal, propriedade independente, em p. 302-335) constituem matéria da oitava parte, sendo realçada a existência de grande fragmentação da propriedade, com tendência para maior divisão por expansão do regime de propriedade horizontal. A autora retoma pontos já tratados na quarta e na sexta partes, mas que se justificam aqui para a melhor compreensão dos problemas. Perpassa constantemente no texto, quer desta última parte, quer doutros locais, o problema da decisão, da acumulação e difusão de decisões que afectam, directa ou indirectamente, a localização e a dimensão da habitação, e da circulação da informação especializada, quer privada, quer pública, quer de transmissão visual. A exploração dessas grandes cate- 
gorias de decisões daria, sem dúvida, outras perspectivas do desenvolvimento urbano ditado pelo mercado de habitação.

Em Nota Final, TERESA M. BARATA SALgueIRo procura sintetizar os grandes problemas tratados nas anteriores 335 páginas de texto denso e rico de ensinamentos.

O que ora apresento em Finisterra foi dito em prova pública de doutoramento, uma vez que me coube argumentar a tese, juntamente com o Arquitecto NUNO RODRIGUES MARTINS PORTAS, especialista de méritos reconhecidos em matérias de que se ocupa a autora da dissertação. Repito-o com muito gosto, em favor do público mais vasto da Revista Portuguesa de Geografia, do Centro de Estudos Geográficos de Lisboa, e, ao mesmo tempo, para deixar fixadas em texto impresso as notas demonstrativas do grande interesse e do indubitável valor de Mercado de Habitação e Estrutura Urbana na Area suburbana de Lisboa, quer do ponto de vista da pesquisa científica, em Geografia urbana, quer do ponto de vista da existência de um documento válido para o reexame de políticas de habitação numa cidade carecente delas, num momento de crise económica e social que aflige o País. 